\title{
Measuring the Utilization of Collaboration Technology for Knowledge Development and Exchange in Virtual Communities
}

\author{
Malte Geib, Christian Braun, Lutz Kolbe, Walter Brenner \\ University of St. Gallen, Institute of Information Management \\ Mueller-Friedberg-Str. 8, 9000 St. Gallen, Switzerland \\ \{malte.geib, christian.braun, lutz.kolbe,walter.brenner\}@unisg.ch
}

\begin{abstract}
The success of a virtual community depends chiefly on the community members' utilization of the community system that supports it. It is therefore essential that the functions of the system meet the members' requirements. The objective of this paper is to identify usage patterns in virtual community systems focused on learning and knowledge exchange in order to derive recommendations for the design of virtual community systems. We therefore analyze two specific professionally-oriented virtual communities focusing on learning and knowledge exchange by indepth case studies.

The first one is a learning network consisting of participants of a post-graduate study program. The second one is an expert network consisting of academic researchers and employees of several major European financial services companies. For each of these two communities, we describe the community's initial situation, its special characteristics, its objectives, its members and different application areas regarding $a$ supporting community system. Thereafter, we identify the requirements that the community system needs to fulfill to satisfy the members' needs. Based on these requirements, the different functions of the system that should meet these requirements, are presented. For each community, we measured the utilization of the functions implemented in the community systems using a web log analysis tool.

Reflecting the measurement results on the case descriptions and the members' requirements, we drew conclusions on how members use a virtual community system: Most importantly, functions that support structured user processes with clear user requirements are preferably used. Moreover, personal information on community members is frequently viewed. On the other hand, most synchronous and asynchronous communi-
\end{abstract}

cation functions are rarely used and community users make few own contributions to discussions. Finally, functions that implement potentially redundant functions, for example group calendars or link collections, are rarely used.

\section{Introduction}

\subsection{Challenges for the design of commu- nity systems}

Communities, or groups of individuals organized informally or semi-formally, are an instrument of knowledge management [5][11][17]. Many companies regard them as a strategic instrument to overcome limitations pertaining to the flexibility and communication of traditional organizational forms such as functional or process-oriented organizations [1][24]. Communities that are geographically dispersed require some sort of communication system to bridge geographical and temporal distances. These communities are called "virtual communities" [19]. A frequently used communication system is an information system based on World Wide Web (WWW) technology (web-based system). These systems, named "community systems", "teamware" [22], or "groupware" [2], support the interactive exchange and creation of documents, online discussions, chat rooms, and role-based personalization. Examples of systems which can be customized to meet the demands of different virtual communities are IBM Lotus Team Workplace (Quickplace), Opentext Livelink, and Documentum eRoom.

The productivity of a virtual community depends heavily on its members accepting the community system that supports it. If the user interface of the community system is too complex, or if the functionalities of the community system do not meet the demands of the users, a lack of utilization may inhibit the community's productivity [3][10]. However, it is difficult to 
design community systems to achieve an optimal utilization. Many community systems therefore lack sufficient utilization [22, p. 178].

\subsection{Research objective and scope}

Our objective is to identify determinants that drive the utilization of virtual community systems. The focus of our research is on professional communities, namely learning networks and expert networks. As such, the target audience we address consists of researchers engaged in research on technologies for virtual communities, professional community managers, and designers of virtual community systems.

\subsection{Research methodology and structure}

To achieve our objective, we analyze two existing virtual communities in-depth: a learning network of postgraduate students and an interorganizational expert network consisting of experts from different companies working in the areas of customer relationship management (CRM) and knowledge management (KM). To analyze both virtual communities, we use a case study research method according to Senger and Österle [23]. First we describe the general characteristics and objectives of each community. Then, based on discussions with community members, we identify roles within the community. For each role, we identify the most important user processes. By identifying the user processes, we derive the requirements of each role concerning the community system.

Contrasting the requirements, we describe each implemented community system and the specific functions it offers community members. We then analyze the utilization of the system on a functional level by means of a web log analysis tool. Based on the measurement results and the initial requirements of the community members, we derive conclusions regarding the utilization of a community system on a functional level.

The next section introduces the theoretical background to virtual communities and the concept of user processes. It additionally gives an introduction to the performance measurement of virtual communities. The third section describes both virtual communities with their objectives, roles, and requirements expected from the supporting community system, as well as the functions of the community systems themselves. In the fourth section, we measure the utilization of functions which are offered by the community systems. The fifth section presents the conclusions that we drew from our analysis. Finally, we summarize our findings, critically review them, and present an outlook on further research opportunities.

\section{Theoretical background}

\subsection{Professionally-oriented virtual com- munities}

The notion "community " is a socio-scientific collective term for a specific type of social group. [16, p. 3][25] Although there is no generally accepted definition, a community can be defined as a group of socially interacting persons who are mutually tied to one another and regularly meet at a common place [8]. With the diffusion of electronic information and communication systems, a new type of community emerged that partly or completely substituted personal meetings with communication via electronic media. The notion "virtual community" was first introduced by Rheingold to describe this phenomenon [19]. Based on the socio-scientific definition of a community, a virtual community is a community that may or may not meet one another face to face, and that may exchange words and ideas through the mediation of telecommunication systems based on computer networks. [cp. 20, p. 116]

Regarding their objectives and scope, virtual communities can be classified into three major types [12, p. 51]: Socially-oriented virtual communities form to support the development of social relationships between individuals without an economic goal. Commercially-oriented virtual communities form to directly support a profitoriented economic goal [cp. 7]. These can further be differentiated into business-to-business and business-to-consumer communities. Constituting the third type, professionally-oriented virtual communities consist of company employees who communicate and share information to support their professional tasks. In this paper, we focus on the analysis of this virtual community type.

Godio defines a professionally-oriented virtual community as follows: "It answers to the need felt by professionals to base their socioprofessional identity on a solid foundation: A reference group broader and more visible that their traditional narrow informal network.[...] They operate across specific work contexts. [...] What is shared is a set of knowledge, values and behavioral norms." [6] 
Professionally-oriented virtual communities can be differentiated into expert networks and learning networks $[12$, p. 51]. As the first subtype, expert networks are formed by experts focused on a specific topic with the aim of acquiring and developing knowledge through their mutual interaction and discussion as members of the network. An expert network emerges through the voluntary association and may be intra- or interorganizational. A socio-scientific explanation of the phenomenon of expert networks is given by Wenger who calls this community type a "community of practice" [26]. Wenger et al. offer a pragmatic definition of expert networks as "groups of people who share a concern, a set of problems, or a passion about a topic, and who deepen their knowledge and expertise in this area by interacting on an ongoing basis." [27, p. 4]

Constituting the second subtype, learning networks are formed by professionals with the objective of joint education, training or learning $[12$, p. 55]. Examples of these are virtual corporate universities [9]. As such, learning networks also focus on knowledge development and exchange as expert networks do. The difference between the two community types is that expert networks further advance and distribute existing expert knowledge with the aim of improving business processes, whereas learning networks educate professionals in an area they do not necessarily need for their current task, thereby not directly improving business processes.

\subsection{Community systems}

As described in the previous section, members of virtual communities interact through the mediation of telecommunication systems based on computer networks. With the propagation of the internet, most systems that support virtual communities are currently based on internet technology. Raimann gives an overview and a classification of internet-based information and communication technologies that can be employed to support virtual communities [18]. We use the term "community system" to describe the internet-based application system that enables the the community members to interact with one another. A community system is mostly implemented as a web-based application that enables the members of a virtual community to communicate and to share information. State-of-the-art community systems comprise functions that support four areas of knowledge management [5]:

- Content: Functions for content management and the exchange of explicated knowledge (documents).

- Competence: Member directories with profiles and competencies.

- Collaboration: Synchronous and asynchronous communication (e.g., email, discussion forums, and instant messaging) and application sharing.

- Composition: Structured navigation and search, and support for structuring based on terminology management.

\subsection{Performance measurement of virtual communities}

Measuring the performance of communities is a challenge, because communities only have an indirect impact on business results. Generally, the performance of communities can be measured on different levels, each with a different impact on business results. McDermott proposes a four-level measurement framework for communities (Fig. 1).

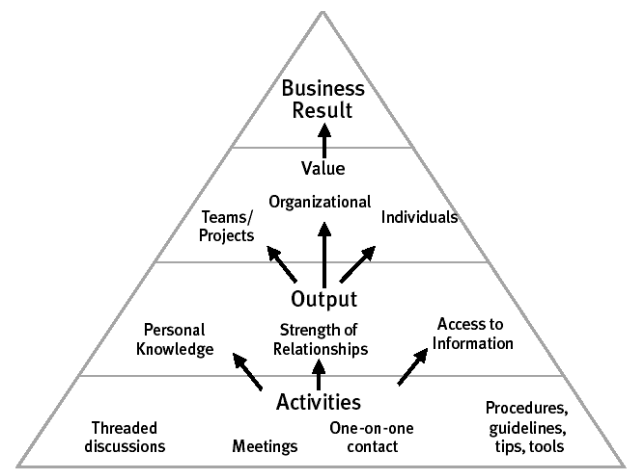

Fig. 1 Performance measurement framework for communities [13]

At the most basic level the community members' activities can be measured. Activities include, e.g., meetings, discussions, and one-toone contacts. Measuring activities can be helpful in giving some indication of the communities' health. However, these measures do not demonstrate the contribution that the community makes to its members or an organization. To determine this contribution, it is necessary to measure the performance of communities in terms of output and value [13].

Focusing on the community systems' contribution to the overall performance of a community, we restrict performance measurement to the activity level. This is necessary, because the community systems' goal is to facilitate the community members' activities and to make them independent of restrictions imposed by space and 
time [3]. Community systems' impact is therefore restricted to the activity level. They influence business results only by facilitating activities.

\subsection{User processes and requirements for community systems}

By measuring community members' activities in a community system, we can obtain an overview of how community members communicate which one another by using the community system. However, to interpret different activity levels, it is necessary to obtain a deeper understanding of the work and the requirements of community members as far as the supporting system is concerned.

To determine user requirements, we use the concept of user processes (also customer processes) [14 pp. 45-50]. A user process is a sequence of activities that are carried out by a customer to resolve a problem or to accomplish a specific task, e.g., attend a course or a workshop. Moreover, a user process defines the services which should be offered by a service provider supporting the user. A service provider should therefore aim at supporting the complete customer process, i.e. each single activity in the process [15]. Transferring this principle to virtual communities and virtual community systems, this means that systems should support each activity in a user process in an interconnected way.

\section{Two case studies of community systems}

We analyzed two professionally-oriented virtual communities, a learning network and an expert network in-depth. For the analysis, we used detailed document and systems analysis as well as complementing discussions with community members. For each virtual community, we identified general objectives, members, and roles. Thereafter we identified use cases for each role of the community members and further deconstructed them into user processes. Based on these user processes, we derived the requirements that the members expect from the community system. Finally, we analyzed the implemented community systems with regard to their functions.

To illustrate similarities and to enhance the generalizability of our findings, we chose two different community subtypes, a learning network and an expert network.

\subsection{The Business Engineering Commu- nity (BEC), a learning network}

\subsubsection{Overview}

The Executive MBA in Business Engineering of the University of St Gallen is a part-time postgraduate course for managers in leading positions. During and after their study the participants are supported by a community system called Business Engineering Community (BEC). Fig. 2 shows the roles of the community members and their corresponding use cases using the notation of the Unified Modeling Language (UML) [21].

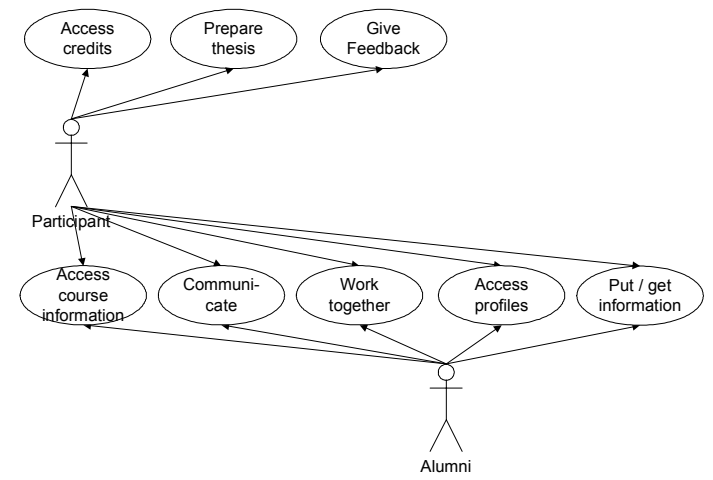

Fig. 2 Roles and use cases of the BEC

The process of the study can be divided into several phases, which are shown in Fig. 3. The phases "introduction" to "alumni" have to be supported by the BEC. Besides this, the BEC has to provide functions that facilitate the development of a community consisting of participants. In the following section, the requirements that the participants have concerning a community system will be derived from the user processes in these phases.

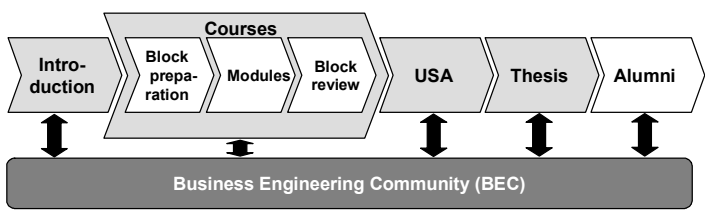

Fig. 3 The process of the study

\subsubsection{Requirements for a community sys- tem}

\section{Requirements of the MBE participants}

In the phase "introduction", the participants need support in order to use the system and to edit their profiles. In the second phase, "block preparation", it is important for the participants to obtain all information on the next course block, such as topics, preparation documents, 
course instructors and timetables. For some blocks, the participants have to do exercises for preparation. These can be done individually or in teams. During a "module", the participants need information about the module, such as topics, timetable, course instructors, meetings and documentation of the meetings. The results of the team work and the discussions have to be documented. The participants must be able to communicate with their company and external persons, for example via email. In the "block review" phase, it is important for the participants to have information about contact persons and a forum in which to discuss a specific block topic. To contribute to the constant improvement of the MBE program, the participants should be able to provide feedback on the module and on all meetings. Finally, each participant should be able to view the credits he obtained. The "USA" block differs from the other block weeks primarily in an increased need for information. Otherwise the requirements are similar to those of the other block weeks. When working on the "thesis", the participants first of all need support to search for topics, to discuss topics, and to decide on a suitable one. Thereafter the system must provide support during the process of thesis writing.

\section{Requirements of the alumni}

After completion of the course, the community's orientation shifts. The learning network now takes on the character of an expert network. The maintenance of a personal network, the exchange of experiences, the search for experts, the organization of events, the search for a (new) job, and information for the solution of a specific problem become important for the alumni.

\subsubsection{Solution}

In order to implement the requirements, the decision was made to use the standard software Lotus Notes/Domino, Lotus Team Workplace (Quickplace 3.0) and Lotus Sametime 3.0. The principal reason for using Lotus products was that the IT infrastructure of the University of St. Gallen is strategically oriented towards IBM and Lotus. The functions of the BEC can be divided into five areas.

- Course Support: Within the "Course" area all information about the modules is available and, if necessary, appropriate documents which can be downloaded. Furthermore, the participants can provide their feedback on a whole study block week and on individual meetings. Every participant can access statistics on his credits achieved so far. To support the participants in their endeavor to find a topic for their thesis, a discussion forum is available in which topics can be suggested and discussed.

- Teamwork: This area offers the participants the opportunity to build teams. Teams can be private or public. They can be used to support the participants' thesis work, to organize joint events, and to support teamwork during a module.

- Communication: The BEC offers both synchronous and asynchronous communication. Synchronous communication is supported by chat or instant messaging, video and audio conferencing, application sharing and a whiteboard. Asynchronous communication is supported by discussion forums and an email system that has been integrated into the BEC.

- Member Profiles: For publication within the $\mathrm{BEC}$, each participant has a personal profile, which he can edit and for which he is responsible.

- Content Administration: The "Content" area contains categorized web content important for participants. Possible content types are book recommendations, citations, links, attachments and events.

\subsection{The CKP-Net, an expert network}

\subsubsection{Overview}

The Competence Center Customer > Knowledge $>$ Performance (CC CKP) is a knowledge network between the Institute of Information Management of the University of St. Gallen (IWI-HSG) and six major Swiss and German financial services companies that finance the competence center. The aim of this network is the development of knowledge in the areas of customer-oriented knowledge management and knowledge-enabled customer relationship management with a focus on performance management.

Generally, the CC CKP consists of a core team - a project manager and researchers of the IWIHSG - and several employees of the participating companies (participants) (see Fig. 4). The network has a steering committee on which each participating company is represented. The steering committee meets biannually to discuss the network's research alignment. 
The task of the core team is to develop knowledge that the participants can use within their companies, while the knowledge network as such should support its participants' work processes. There are four different modes of knowledge exchange between the core team and participants: workshops, project work / action research, case study research, and literature research.

Workshops are conducted four times a year and deal with varying topics. During a workshop the core team members present state-of-the-art concepts and future trends, whereas the participants report on the status of related projects in their companies and the challenges that they currently face. The core team and participants also take part in group work to exchange knowledge on a new area of research. Workshops therefore support the transfer of knowledge from the core team to the participants as well as vice versa.

To further encourage mutual knowledge exchange, the core team members also support the employees of the participating companies through projects within their respective companies. This project support occurs by means of an action research framework. The core team also carries out case study research within the companies belonging to the network . Literature research for these companies complement the knowledge transfer.

\begin{tabular}{|c|c|c|}
\hline \multicolumn{3}{|c|}{ Workshops } \\
\hline \multirow{3}{*}{$\begin{array}{c}\text { Core Team } \\
\text { (IWI-HSG) }\end{array}$} & Project work / Action research & \multirow{3}{*}{$\begin{array}{l}\text { Participants } \\
\text { (partner companies) }\end{array}$} \\
\hline & Case study research & \\
\hline & Literature research & \\
\hline
\end{tabular}

Fig. 4 Organization and knowledge transfer within the CC CKP

\subsubsection{Requirements for a community sys- tem}

The transfer of knowledge from core team to participants is especially important for the knowledge network. The core team therefore decided to implement a virtual community system to support knowledge exchange and transfer in the competence center.

Because the system was designed to support knowledge transfer towards the participants and steering committee members, we focus on these two groups of stakeholders' requirements. Fig. 5 shows both roles and their respective use cases for the CKP-Net.

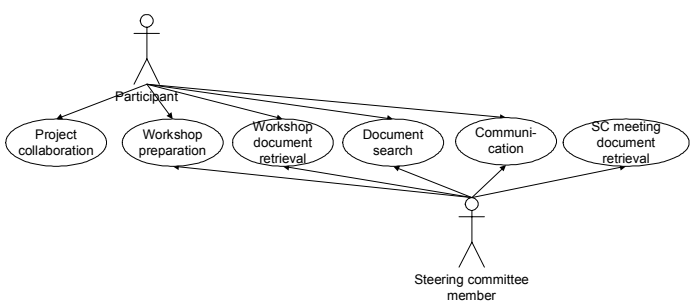

Fig. 5 Roles and use cases of the CKP-Net

Project work that the participants and core team carry out, requires an intensive exchange of documents, e.g., documents explaining the enterprise environment, project plans, and concepts. The CKP-Net therefore has to facilitate the exchange of documents and the collaborative creation of documents.

Both the steering committee members and the participants are involved in the preparation of workshops. The steering committee members of each company have to select participants to attend such a workshop. The selected participants then have to prepare for the workshop by familiarizing themselves with the topics of the workshop.

After a workshop, many of the participants and steering committee members need to access the presentations and results of group work for utilizing in their own work.

Apart from the workshop documents, the participants and steering committee members often need documented knowledge on a specific topic, e.g., for projects that are not carried out in collaboration with the competence center. Therefore the CKP-Net has to support the publication of research documents and a topic-oriented structured search.

In order to build strong relationships within the competence center, it is useful for the core team, participants, and steering committee to communicate with one another at times other than during the workshop meetings. Contact details of all stakeholders should therefore be published within the CKP-Net.

Lastly, it should be possible to publish agendas, presentations, and the results of discussions in steering committee meetings on the CKP-Net to allow the steering committee members easy access to these.

\subsubsection{Solution}

The CKP-Net has been implemented using Lotus Team Workplace (Quickplace 3) and Lotus Sametime 3. This was due to an existing IT landscape with a clear focus on IBM and Lotus products. Based on the requirements described in the 
previous section, the solution comprises the following functions:

- General information: This tab contains documents with a project plan, a list of publications, and important links.

- Team information: Two documents provide the contact information of core team members, participants, and steering committee members, as well as photos of the core team members.

- Workshops: This tab includes documents pertaining to planned and conducted workshops (information on location, agenda, workshop presentations, and photos of conducted workshops).

- Research Topics: Included under this tab are several academic papers and presentations dealing with research topics that are relevant to the participants and steering committee members.

- Project Rooms: Each of the participating companies has its own collaborative workspace that can be accessed via this tab. A workspace includes support for the exchange and collaborative creation of documents as well as discussion forums.

- Steering committee: This tab contains documents about planned and conducted steering committee meetings (information on location, agenda, presentations, and photos of conducted steering committee meetings).

- Archive: Integrated under this tab are workshop documents and documentation of specific research topics of past competence centers.

- Chat: By clicking on the Chat button, each user of the CKP-Net can activate an integrated Lotus Sametime client application for awareness and instant messaging (AIM). This client application also provides opportunities for audio and video meetings as well as application sharing.

- Support functions: Further support functions include integrated help, a feedback function, search and news functions.

\subsection{Case comparison}

Figallo offers classification criteria for virtual communities based on the behavior of the community members $[4$, p. 35]. We use this criteria for comparison to show similarities.

- Degree of personal interactivity: Both communities include a high degree of interactivity during personal meetings (courses and workshops). Contrariwise, interaction using the community systems is moderate and confines itself to the absolutely necessary.

- Subject scope: The subject scope in both communities is relatively narrow, as both of them deal with a specific subject area. In the case of the BEC, this is "Business Engineering", in the case of the CKP-Net, this is "customer-oriented Knowledge Management".

- Cohesion of members: In both cases, the cohesion of members is sustained by a semiformal organization, in the case of the CKPNet the course organization, and in the case of the CKP-Net the organization of the competence center.

The main difference between both communities is that the competence center CKP focuses on the development of new knowledge (and consecutively its dissemination within the community and beyond, whereas the Executive Master of Business Engineering course focuses on learning, i.e. the dissemination of already existing knowledge.

\section{Performance Measurement}

We measured the utilization of the specific functions implemented in the CKP-Net and BEC (see previous section). The starting point of the analysis was the access logs generated by the web server (Lotus Domino server) that handles the communication between the community members and community applications (Lotus Notes databases, Lotus Team Workplace and Lotus Sametime). We analyzed the access logs, using the web log analysis tool "WebTrends", which can cope with the specificities of access logs generated by a Domino server. To eliminate effects imposed by the administration of a community system (which also generates entries in the access logs), we filtered the entries containing user names and internet protocol (IP) addresses of administrators (e.g., the core team of the CC CKP). Consequently, the results of the analysis only contain the activities of those community members who do not administrate the community systems.

Aggregating the results, we determined how often each functional area of the community systems (described in the previous section) was 
used by the community members. Fig. 6 shows the results as they relate to the CKP-Net.

The first row contains the functions identified in the previous section. The second row (page views) indicates how often a document related to the specific function was viewed. For example, the figure " 36 " in the first column indicates that documents related to "General information" (project plan, list of publications, and important links) were accessed 36 times by the users. The third row shows the percentage of page views in relation to the total number of page views (995). This percentage is an indicator of how important the specific function is for the users.

\begin{tabular}{|l}
\begin{tabular}{|l|c|c|c|c|c|}
\hline & General Info & $\begin{array}{c}\text { Team } \\
\text { Info }\end{array}$ & Workshops & $\begin{array}{c}\text { Research } \\
\text { Topics }\end{array}$ & $\begin{array}{c}\text { Project } \\
\text { Rooms }\end{array}$ \\
\hline page views & 36 & 154 & 620 & 63 & 40 \\
\hline $\begin{array}{l}\% \text { of total } \\
\text { page views }\end{array}$ & $3.62 \%$ & $15.48 \%$ & $62.31 \%$ & $6.33 \%$ & $4.02 \%$ \\
\hline & $\begin{array}{l}\text { Steering } \\
\text { Committee }\end{array}$ & Archive & Chat & Support & Sum \\
\hline $\begin{array}{l}\text { page views } \\
\text { \% of total } \\
\text { page views }\end{array}$ & 36 & 46 & 0 & 0 & 995 \\
\hline
\end{tabular}
\end{tabular}

Fig. 6 Use of functions in the CKP-Net (February to May 2003)

\begin{tabular}{|c|c|c|c|c|c|c|c|}
\hline & \multicolumn{5}{|c|}{ Course Support } & Teamwork \\
\hline & Module & $\begin{array}{c}\text { Feedback } \\
\text { Block } \\
\text { Weeks }\end{array}$ & $\begin{array}{c}\text { Feedback } \\
\text { Meetings }\end{array}$ & Credits & $\begin{array}{c}\text { Topic } \\
\text { Bourse }\end{array}$ & $\begin{array}{c}\text { Finished } \\
\text { Topics }\end{array}$ & Teams \\
\hline page views & 6822 & 1453 & 150 & 22 & 4231 & 4726 & 5968 \\
\hline $\begin{array}{c}\% \text { of total page } \\
\text { views }\end{array}$ & $15.96 \%$ & $3.40 \%$ & $0.35 \%$ & $0.05 \%$ & $9.90 \%$ & $11.06 \%$ & $13.96 \%$ \\
\hline
\end{tabular}

\begin{tabular}{|c|c|c|c|c|c|c|c|}
\hline & \multicolumn{3}{|c|}{ Communication } & Profiles & \multicolumn{2}{|c|}{ Administration } & \\
\hline & Chat & $\begin{array}{c}\text { General } \\
\text { Discussion }\end{array}$ & $\begin{array}{c}\text { Course } \\
\text { Discussion }\end{array}$ & Members & Content & Browse & SUM \\
\hline $\begin{array}{c}\text { page views } \\
\text { of total page } \\
\text { views }\end{array}$ & $1.02 \%$ & 1784 & 5909 & 7022 & 1317 & 2905 & 42745 \\
\hline
\end{tabular}

Fig. 7 Use of functions in the BEC (February to May 2003)

Fig. 7 shows the results as they relate to the BEC. The first row contains the five areas of the BEC. The second row contains the corresponding functions for each area.

\section{Conclusions and discussion}

Based on the measurement results of the previous section, combined with the insights we gained from the detailed analysis of both virtual communities in section 3, we derived five conclusions about the use of community systems in professionally-oriented virtual communities:

1. Functions that support structured user processes with clear user requirements are preferably used.
We can see that the most frequently visited area in the CKP-Net was "Workshops", in the case of the BEC, this was "Course Support". Both areas support requirements directly connected to structured user processes, i.e. "attending workshops" and "attending courses" are structured user processes with clearly defined activities. We suspect that because the community systems focus on supporting these structured processes, community members benefit directly from the supporting functions which increases utilization of these functions. Conversely functions that do not support clearly structured user processes, e.g. "Administration" in the BEC, and "Research topics" and "Archive" in the CKPNet, are not frequently used.

\section{Personal information on community mem-} bers is frequently viewed.

In both community systems the member profiles area was the second most frequently accessed area. This was a surprise, because most of the community members of both communities meet personally on a regular basis either in workshops, or in courses, and can therefore exchange personal information during these events. However, it seems to be important for the community members to obtain detailed personal information on other community members via the system, e.g., information on their company, job description, and work areas. We suspect that this is the case because personal contact during community events is insufficient due to time constraints and the number of community members. A community system offers a means of obtaining further personal information and to extend the personal network.

\section{Most synchronous and asynchronous} communication functions are rarely used.

Most of the functions for synchronous or asynchronous communication in the CKP-Net and BEC are only rarely used by community members. For example, the chat function in the CKP-Net was never used and the project rooms were rarely used. In the BEC, chat and general discussion too were rarely used. In contrast, in the BEC the teamwork area and the course discussion area were used quite frequently. We suspect that the intensity of use of a specific communication function within a community system depends on whether the function can support a specific communication demand of the members better than other means of communication. In the $\mathrm{BEC}$ for example, teamwork areas and course 
discussion areas may be frequently used because they address a specific member need and are therefore superior to other modes of communication, e.g. telephone, email, because teams and courses consist of several geographically dispersed people. To support this assumption, further empirical work has to be carried out.

4. Community users make few own contributions.

While the course discussion forums in the BEC are frequently viewed, the number of contributions is small compared to the number of page views generated by members following the discussion. We suspect that community members are interested in following discussions, but most of them do not want to spend time on answering or actively taking part. This assumption has to be supported by further research. Moreover, in the BEC the function to provide feedback on courses and modules was rarely used. In the CKP-Net, no feedback was given by the community members at all.

5. Functions that implement potentially redundant functions are rarely used.

We believe that several functions, especially in the BEC, are not used because the members may use other application systems that satisfy similar demands. For example, the content area in which community members can categorize their favorite links, may not be needed because members do so within their web browser. The content function within the BEC may consequently be redundant. The same may be true for team calendars in the teamwork area as most people organize their time within a personal calendaring system such as Microsoft Outlook or Lotus Notes. To support this assumption, further empirical research has to be carried out.

\section{Summary \& Outlook}

Based on the performance measurement on an activity level and two in-depth case studies of professionally-oriented virtual communities, a learning network and an expert network, we drew five conclusions on the use of technology in community systems to support professionallyoriented virtual communities:

- Functions that support structured user processes with clear user requirements are preferably used.

- Personal information on community members is frequently viewed.

- Most synchronous and asynchronous com- munication functions are rarely used.

- Community users make few own contributions.

- Functions that implement potentially redundant functions are rarely used.

It is therefore necessary for systems that support virtual communities that the implemented functions are customized to support user processes associated with the specific community. If the functions do not directly support user processes, or support tasks that are already supported by other systems (e.g., calendaring), this will result in a lack of utilization. Moreover, the system has to offer the opportunity to publish the personal and work contexts of the community members in order to facilitate mutual exchange.

Critically reviewing our work, it was possible to draw conclusions for the utilization of technology from the two case studies, but it is necessary to carry out further empirical research to interpret our findings and to learn what motivates the community members' usage of the systems, e.g. by collecting survey data.

We furthermore abstracted from some factors that may have an influence on the utilization of a community system, e.g. interface design, training, and change management activities. To further analyze the influence of other factors on the utilization of community technology, further research needs to be conducted.

One important question remaining to be answered is what influence the design of functions in a community system has on the overall performance of a virtual community. To answer this question, we have to analyze and combine measurement results from different performance levels (activities, output, and value; see section 2.3). Currently, we are working on metrics to measure performance in both analyzed communities in terms of output and value. Our research objective is to show the link between the use of technology and the business results of a virtual community.

\section{References}

[1] Bach, V., Österle, H. and Vogler, P., Business Knowledge Management in der Praxis [Business Knowledge Management in practice], Springer, Berlin, 2000.

[2] Bach, V., Vogler, P. and Österle, H. (Eds.), Business Knowledge Management, Springer, Berlin et al., 1999.

[3] Bieber, M., Engelbart, D., Furuta, R., Hiltz, S. R., Noll, J., Preece, J., Stohr, E. A., Turoff, M. and van de Walle, B., "Toward Virtual Community Knowledge 
Evolution", Journal of Management Information Systems, Vol. 18, No. 4, 2002, pp. 11-35.

[4] Figallo, C., Hosting Web Communities: Building Relationships, increasing Customer Loyalty, and maintaining a competitive Edge, John Wiley \& Sons, New York, 1998.

[5] Gebert, H., Geib, M., Kolbe, L. M. and Brenner, W., "Knowledge-enabled Customer Relationship Management - Integrating Customer Relationship Management and Knowledge Management Concepts", Journal of Knowledge Management, Vol. 8, No. 1 (February), 2004, forthcoming.

[6] Godio, C., "Building a Virtual Professional Community: The Case of Poolweb.it", The Third International Conference on Virtual Communities, London, 2000.

[7] Hagel, J. and Armstrong, A. G., Net Gain: Expanding markets through virtual communities, Harvard Business School Press, Boston (MA), 1997.

[8] Hillery, G. A., "Definitions of Community: Areas of Agreement", Rural Sociology, Vol. 20, 1955, pp. 118-125.

[9] Kraemer, W. and Müller, M., "Virtual Corporate University: Executive Education Architecture and Knowledge Management", in: Scheer, A.-W. (Ed.) Electronic Business und Knowledge Management, Physica, Heidelberg, 1999.

[10] Majchrzak, A., Rice, R. E., Malhotra, A., King, N. and Ba, S., "Technology adaption: The case of a computer-supported inter-organizational virtual team", MIS Quarterly, Vol. 24, No. 4, 2000, pp. 569-600.

[11] Malhotra, Y. (Ed.) Knowledge Management and Virtual Organizations, Book Crafters, Hershey, 2000.

[12] Markus, U., Integration der virtuellen Community in das Customer Relationship Management [Integration of virtual communities into Customer Relationship Management], Dissertation, University of the Saarland, Saarbrücken, 2002.

[13] McDermott, R., "Measuring the impact of communities", Knowledge Management Review, Vol. 5, No. 2, 2002, pp. 26-29.

[14] Österle, H., "Enterprise in the Information Age", in: Österle, H., Fleisch, E. and Alt, R. (Eds.), Business Networking: Shaping Collaboration Between Enterprises, 2nd, rev. and extended ed., Springer, Berlin et al., 2001, pp. 17-54.
[15] Österle, H. and Blessing, D., "Business Engineering Model", in: Österle, H. and Winter, R. (Eds.), Business Engineering, Springer, Berlin etc., 2000, pp. 61-80.

[16] Poplin, D. E., Communities - A Survey of Theories and Methods of Research, 2 ed., Mcmillan, New York, 1979.

[17] Probst, G. J. B., Raub, S. and Romhardt, K., Wissen managen - Wie Unternehmen Ihre wertvollste Ressource managen [Managing knowledge], Gabler, Wiesbaden, 1997.

[18] Raimann, J., Unterstützung von Wissensnetzwerken mit I-Net-basierten Informationsund Kommunikationstechnologien [Supporting knowledge networks with internet-based information and communication technologies], Dissertation, Universität St. Gallen, St. Gallen, 2002.

[19] Rheingold, H., The Virtual Community: Homesteading on the Electronic Frontier., Addison-Wesley, Reading (MA), 1993.

[20] Rheingold, H., "Virtual Communities", in: Hesselbein, F. (Ed.) The Community of the Future, JosseyBass, San Francisco, 1998.

[21] Rumbaugh, J., Jacobson, I. and Booch, G., The Unified Modeling Language Reference Manual, Addison-Wesley, 1998.

[22] Schulte, T., Group Computing Workspace, Dissertation, University of St. Gallen, St. Gallen, 1999.

[23] Senger, E. and Österle, H., PROMET BECS - A Project Method for Business Engineering Case Studies, Research Report, Institute of Information Management, University of St. Gallen, St. Gallen, 2002.

[24] Skyrme, D. J., Knowledge Networking: Creating the Collaborative Enterprise, Reed Educational and Professional Publishing, Woburn, 1999.

[25] Sutton, W. A. and Munson, T., Definitions of Community, Research Report, American Sociological Association, New York, 1976.

[26] Wenger, E., Communities of Practice: Learning, Meaning, and Identity, Cambridge University Press, Cambridge, 1997.

[27] Wenger, E., McDermott, R. and Snyder, W. M., Cultivating communities of practice: a guide to managing knowledge, Harvard Business School Press, Boston (MA), 2002. 